\title{
Supportive care for the critically ill neonatal foal
}

\author{
Bettina Dunkel \\ The Royal Veterinary College, Department of Veterinary Basic Sciences, North Mymms, UK
}

\begin{abstract}
Intensivbehandlung kritisch erkrankter neugeborener Fohlen
Neugeborene Fohlen sind anfällig fuer eine Vielzahl von Erkrankungen. Besonders schwerwiegend und unter Umständen lebensbedrohlich sind das perinatale Asphyxie-Syndrom (PAS) und Sepsis, die signifikanten Störungen vieler Organfunktionen verursachen können. Unabhängig von der zu Grunde liegenden Erkrankung sind die Prinzipien der Behandlung kritisch kranker Fohlen ähnlich. Stabilisierung des Flüssigkeits-, Elektrolyte und Säure-Basenhaushalts, sowie Optimierung der Funktionen des Herz-Kreislauf- und Lungensystems zur Verbesserung der Durchblutung und Sauerstoffversorgung periphere Organe ist neben Behandlung der primären Krankheitsursache von größter Wichtigkeit. Akute Hypovolämie und Dehydratation können durch Verabreichung von Schockdosen einer isotonischen Infusionslösung ausgeglichen werden, während hypotonische Lösungen mit geringeren Natrium- und höheren Kaliumkonzentrationen zur Deckung des Erhaltungsbedarfs besser geeignet sind. Falls durch Infusionstherapie alleine keine ausreichende periphere Durchblutung erreicht werden kann, besteht die Möglichkeit, Herzleistung und peripheren Gefäßwiderstand pharmakologisch zu beeinflussen. Die Respirationsfunktion kann durch intranasale Sauerstoffzufuhr, medikamentelle Verbesserung der Atemfunktion oder mechanische Ventilation optimiert werden. Bluttransfusionen zur Erhöhung der Sauerstofftransportkapazität sind in einigen Patienten ebenfalls angezeigt. Enterale oder, falls notwendig, intravenöse Ernährung des Fohlens sind ebenfalls im Behandlungsplan zu berücksichtigen. Mit entsprechender Unterstützung und Betreuung können viele, auch schwerkranke Fohlen ohne bleibende Folgeschäden überleben.
\end{abstract}

Schlüsselwörter: Fohlen, Intensivtherapie, Infusionstherapie, Herz-Kreislaufunterstützung, Respirationstrakt

\section{Summary}

Equine neonates may suffer from a variety of diseases; perinatal asphyxia syndrome (PAS) and neonatal sepsis are particular severe, often life-threatening diseases that have the potential to affect homoeostasis of many organ systems. Regardless of the underlying disease process, some general principles apply to the treatment of any critically ill neonatal foal. Maintenance of a normal fluid, electrolyte and acidbase balance as well as cardiovascular and pulmonary function to ensure adequate perfusion and oxygen delivery to peripheral organs is one of the most important aspects of supportive care. Hypovolaemia and dehydration are addressed by administration of boluses of a balanced electrolyte solution while maintenance fluid requirements are best met using a hypotonic solution with a low sodium and a higher potassium content. If fluid therapy alone does not improve peripheral perfusion, use of inotropes and vasopressors may be indicated. Hypoxaemia can be combated by intranasal oxygen insufflation, pharmacological stimulation of the respiratory centre or mechanical ventilation. Blood transfusions may be necessary to improve the oxygen carrying capacity in certain patients. Enteral or parenteral nutrition also constitute an essential part of the treatment plan. With adequate supportive care even critically ill equine neonates can survive and develop into normal foals.

Key words: Foal, equine neonate, supportive care, fluid therapy, critically ill, cardiovascular support

\section{Introduction}

Neonatal foals may suffer from a variety of disorders affecting one or more body systems; many are relatively mild, non-life threatening diseases readily addressed by the attending veterinarian on the farm. Others, in particular perinatal asphyxia syndrome (PAS) and neonatal sepsis, require intensive medical therapy that often can only be accomplished in well equipped referral hospitals. Regardless of the underlying primary disease process, several general treatment guidelines apply to any critically ill neonate. In addition to addressing the primary disorder, establishing adequate perfusion and oxygenation of all organ systems, sustaining a normal fluid and electrolyte balance and providing nutrition are important aspects of any therapeutic plan. Due to the often rapid changes and frequent occurrence of secondary complications that may be encountered when treating foals close monitoring of the patient's progress and responses to treatment and interventions also constitute an essential part of neonatal critical care. After a brief discussion of the physiology and patho- physiology of tissue oxygenation, the article focuses on supportive care for critically ill equine neonates. Aspects of fluid therapy and cardiovascular support, improvement of oxygen transport and nutrition for the compromised foal are discussed with an emphasis on problems occurring in foals suffering from PAS and/or sepsis. Monitoring of progression and response to therapeutic interventions are discussed briefly; for more in depth review of monitoring of the critically ill patient, the reader is referred to a recent review article focusing on this topic (Magdesian 2004).

\section{Physiology and pathophysiology of tissue oxygenation}

The cardiovascular and respiratory systems work in unison to achieve adequate $\mathrm{O}_{2}$ delivery to the peripheral tissues. If $\mathrm{O}_{2}$ delivery becomes compromised, ultimately severe organ damage will result. The cardiovascular system maintains blood flow to the tissues; blood flow relies on an adequate 
cardiac output (CO), a sufficient driving force (the gradient between mean arterial and central venous pressure, $\Delta P=$ MAP-CVP; clinically often substituted by MAP) and a force essential to build and maintain the driving pressure gradient, the systemic vascular resistance (SVR). The relationship of the three parameters can be expressed in the following equation: $M A P=C O \times S V R$. It is obvious from this equation that MAP can be increased by increasing either CO or SVR, emphasising that a normal or increased MAP does not necessarily equal normal blood flow.

$\mathrm{CO}$ is defined as the amount of blood ejected by each ventricle per minute and is dependent on stroke volume (SV) and heart rate (HR). The cardiac index (Cl) expresses $\mathrm{CO}$ per $\mathrm{kg}$ body weight or $\mathrm{m}^{2}$ surface area. SV is determined by 3 factors: preload (end-diastolic volume; EDV), cardiac contractility and SVR, while CO, in addition to these 3 factors, also depends on HR. Clinically, end-diastolic pressure (EDP) or central venous pressure (CVP) may be used as surrogate measurements for EDV, providing cardiac compliance is normal.

In the critically ill foal, decreases in preload occur commonly due to absolute or relative hypovolaemia or dehydration, resulting in an immediate decrease in SV and decreased peripheral perfusion. Preload can be improved by correction of hypovolaemia thereby re-establishing a normal EDV. Cardiac contractility may also be reduced in compromised neonates, additionally decreasing $\mathrm{CO}$. There is some evidence that myocardial injury occurs in septic foals, based on increased serum cardiac troponin T (cTNT) and the cardiac isoenzyme of creatine kinase (CKMB) concentrations found in septic foals (Slack et al. 2005). Although no measures of cardiac function were reported in this study, it is conceivable that cardiac performance is negatively affected in these animals. Cardiac contractility can be improved by increasing preload, as described by the Frank-Sterling law, and by pharmacologic manipulation of the autonomous nervous system, namely by administration of inotropic agents acting on $\beta 1$-adrenergic receptors. Decreased SVR, a feature of hyper- and hypodynamic shock, is due to a failure of the vascular smooth musculature to constrict in response to appropriate stimuli, which leads to the inability to maintain a pressure gradient across the vascular beds and, with lack of a driving force, decreased perfusion of the end organs (Corley 2004). Use of vasopressors, either acting on $\alpha$-adrenergic or vasopressin 1 (V1) receptors of the arterial vascular smooth muscle, re-establishes vascular tone and the driving pressure gradient, resulting in improved blood flow to the affected area.

Hypoxia describes decreased $\mathrm{O}_{2}$ supply at the tissue level while hypoxaemia is defined as decreased $\mathrm{CaO}_{2}$ in the arterial blood. Tissue hypoxia may be a result of a decreased arterial $\mathrm{O}_{2}$ content $\left(\mathrm{CaO}_{2}\right)$, decreased perfusion or inadequate $\mathrm{O}_{2}$ uptake by the tissues. $\mathrm{CaO}_{2}$ depends on effective respiration, concentration of $\mathrm{O}_{2}$ in the inspired gases $\left(\mathrm{FiO}_{2}\right)$, efficient gas exchange in the lungs and an adequate $\mathrm{O}_{2}$ transport in the blood, mainly determined by the concentration of haemoglobin.

Therapeutically, one of the main goals is to maintain a normal or close to normal $\mathrm{O}_{2}$ delivery $\left(\mathrm{DO}_{2}\right)$ to the tissues to prevent hypoxia. $\mathrm{DO}_{2}$ is directly proportional to $\mathrm{CO}$ and $\mathrm{CaO}_{2}$; and an increase in $\mathrm{DO}_{2}$ can be achieved by either enhancing $\mathrm{CO}$ or $\mathrm{CaO}_{2}$ or both. $\mathrm{CO}$ can be augmented by increasing the preload and maintaining a sufficient circulatory volume, increasing cardiac contractility or establishing a normal vascular tone in order to allow building of a pressure gradient and blood through the tissues. $\mathrm{CaO}_{2}$ can be manipulated by increasing $\mathrm{FiO}_{2}$ and respiratory efficiency and by optimising the $\mathrm{O}_{2}$ carrying capacity of the blood.

\section{Fluid therapy and cardiovascular support}

Fluid therapy is indicated in any compromised neonate unable to maintain a normal intravascular volume and/or a normal fluid, electrolyte and acid base balance. This includes any foal unable to nurse for any reason, foals with increased fluid losses, mainly due to diarrhoea or colic, foals with primary electrolyte abnormalities, for example cases of uroperitoneum and enteritis, and foals with haemodynamic instabilities, frequently encountered in neonates with sepsis or PAS. In adult equine patients with a functional renal system, minor, and even larger, mistakes in fluid therapy are often forgiven due to the ability of the kidney to maintain homeostasis even under suboptimal conditions. The same does not account for neonates, as firstly, they are still in various stages of transition from a fetal fluid balance, only gradually approaching adult values during the first days to weeks of life, and secondarily, regulatory systems may be compromised by the primary disease process. Meticulous attention should therefore be directed towards avoiding over- or dehydration and maintaining an adequate electrolyte balance; the differences between fetal, neonatal and adult fluid balance has been reviewed elsewhere (Palmer 2004).

Fluid therapy is achieved through an indwelling 16ga or $14 \mathrm{ga}$ intravenous catheter either by providing fluid boluses or a continuous infusion. In ambulatory foals sharing a stall with the mare fluid boluses are the most practical option, but any critically ill foal in need of cardiovascular support will require continuous infusions, best delivered with the aid of a fluid pump. Fluid therapy is divided into immediate resuscitation measurements for initial stabilization, usually with the aim of enabling end organ perfusion as quickly as possible, but occasionally also to correct electrolyte abnormalities, mainly hyperkalaemia and hypo- or hypernatraemia. Once the initial goal has been achieved, the patient is switched to a fluid plan aimed towards maintaining normal or close to normal homeostasis.

\section{Fluid resuscitation}

Acute hypovolaemia should be corrected as rapidly as possible to ensure adequate end organ perfusion. Balanced electrolyte solutions given as $10-20 \mathrm{ml} / \mathrm{kg}$ boluses over $10-20 \mathrm{~min}$ with or without the addition of colloids (plasma at $10 \mathrm{ml} / \mathrm{kg} / \mathrm{h}$; total volume of 1.0-2.0L or a synthetic colloid, such as hetaor pentastarch at $3-5 \mathrm{ml} / \mathrm{kg}$ as a bolus up to a maximum of $10 \mathrm{ml} / \mathrm{kg} / \mathrm{d}$ ) may be used initially. After each bolus, the patient should be reassessed and boluses repeated as necessary until signs of improved peripheral perfusion are evident (Magdesian 2005, Palmer 2004). Signs reflecting sufficient intravascular volume replacement may include improved pulse quality, 
arterial filling, capillary and jugular refill time and mucous membrane color. More objective measurements of the volume status of the patient can be obtained by measurement of central venous pressure (CVP) (Magdesian and Madigan 2003). Normal values for neonatal foals have been reported to be $2.8-12 \mathrm{cmH}_{2} \mathrm{O}$ during the first 2 weeks of life (Thomas et al. 1987). Clinically, a low CVP is often more revealing as it strongly indicates insufficient volume replacement while a CVP within the normal range does not necessarily rule out hypovolaemia.

Clinical signs for improve peripheral perfusion include better peripheral pulse quality, warming of the distal limbs, increased urine output and borborygmi and improved mental status, indicating normalisation of peripheral, renal, gastrointestinal and central perfusion, respectively. Increasing MAP and decreasing blood lactate concentrations over time are also favorable signs, but are best used in conjunction with the overall clinical picture. An increased MAP without improvement of clinical and laboratory signs of adequate perfusion can not be taken as an indicator of improved blood supply to the tissues.

If no progress in peripheral perfusion has been achieved despite signs of appropriate intravascular volume (usually after rapid administration of $60-80 \mathrm{ml} / \mathrm{kg}$ corresponding to 3 5 boluses), additional haemodynamic support is necessary (see below) (Palmer 2004). Once intravascular volume is replenished, the infusion should be changed to an appropriate maintenance fluid type and rate.

\section{Fluid maintenance}

Foals that do not receive enteral nutrition in form of milk require intravenous administration of fluids to provide maintenance requirements of free water and electrolytes. Critically ill foals receiving fluid therapy, particularly those suffering from sepsis and PAS, are prone to overhydration and development of peripheral oedema. The increased tendency to oedema formation may be associated with a combination of differences in sodium handling by neonates, predisposing them to sodium overload and fluid retention as well as renal compromise, and increased capillary permeability induced by the primary disease process. Traditionally, $80-120 \mathrm{ml} / \mathrm{kg} / \mathrm{d}$, depending on the age of the foal, have been used to estimate maintenance fluid requirements for equine neonates; a $50 \mathrm{~kg}$ foal would therefore receive a maintenance rate of $170-250 \mathrm{ml} / \mathrm{h}$. Other clinicians favor a "dry" maintenance rate based on the Holliday-Seger formula: for the first $10 \mathrm{~kg}$ of body weight, $100 \mathrm{ml} / \mathrm{kg}$ are administered, then $50 \mathrm{ml}$ for each $\mathrm{kg}$ from $11-20 \mathrm{~kg}$ and $25 \mathrm{ml}$ for each $\mathrm{kg}$ of body weight $>20 \mathrm{~kg}$. Using this calculation, maintenance fluid requirements for a $50 \mathrm{~kg}$ foal are $2250 \mathrm{ml} / \mathrm{d}$ or a maintenance rate of $94 \mathrm{ml} / \mathrm{h}$ (Palmer 2004) $(10 \mathrm{~kg} \times 100 \mathrm{ml} / \mathrm{kg} / \mathrm{d}+10 \mathrm{~kg} \times$ $50 \mathrm{ml} / \mathrm{kg} / \mathrm{d}+30 \mathrm{~kg} \times 25 \mathrm{ml} / \mathrm{kg} / \mathrm{d}$ ) plus fluids received with parenteral nutrition and medication infusions. It is important to note that parenteral nutrition, although strictly speaking not representing intravenous fluids, adds free water to the total fluid volume administered and that this maintenance formula is not intended to be used in foals with increased fluid losses, such as diarrhoea. As no controlled study has compared the two fluid regimes and both have been used clinically with suc- cess, the clinician may choose either protocol as a starting point from which fluid therapy is then tailored to the needs of the individual patient.

Signs of fluid retention and sodium overload may be subtle, manifesting as net fluid retention (net fluid ins $>>$ net fluid out), mild to moderate oedema, particularly in the axillary region and on the peripheral limbs or inappropriate weight gain. Central venous pressure (CVP), if measured, mainly indicates intravascular volume and may not adequately reflect fluid retention in the interstitial space. Signs of dehydration and/or insufficient intravascular volume are clinically easier to recognise as already discussed.

The choice of maintenance fluids depends largely on the individual patient. Administration of fluids containing sodium concentrations close to plasma concentrations has been discouraged as neonates of other species have been reported to be prone to sodium overload and subsequent fluid retention (Palmer 2004). This may not be the case in foals as a recent study using 4 day old healthy foals demonstrated no evidence for sodium or fluid retention, but increased sodium excretion in response to intravenous administration of fluids containing a physiologic sodium concentration (Buchanan et al. 2005). However, the situation may be very different in younger or compromised neonates. As the study also found net whole body potassium losses, potentially associated with the infusion-induced natriuresis, the authors suggested that fluids containing lower sodium and higher potassium concentrations, such as commercially available maintenance fluids, may be a more appropriate choice for equine neonates (Buchanan et al. 2005). Maintenance fluids differ in their composition from resuscitation fluids: they are hypoosmolar compared to the extracellular fluid, allowing distribution of water to the intracellular space. The lower sodium and higher potassium content match closer the natural electrolyte intake of a nursing foal as mare's milk is low in sodium (Magdesian and Madigan 2003). Maintenance fluids can be tailored to the individual needs of each patient by administering $1 / 2$ to $2 / 3$ of the calculated volume as $5 \%$ dextrose in water (D5W) and substituting the remaining volume with resuscitation fluids and additional potassium supplementation as necessary (Magdesian and Madigan 2003).

\section{Cardiovascular support}

If adequate peripheral perfusion can not be established by improving intravascular volume and preload alone, further cardiovascular support in form of inotropes and/or vasopressors is necessary. As discussed previously, an increased MAP can be achieved by either CO output or increasing SVR and an improved MAP therefore does not always represent improved blood flow to the tissues.

\section{Inotropes}

Once intravascular volume and preload have been optimised, one can attempt to further increase $\mathrm{CO}$ by enhancing cardiac contractility. Dobutamine (DOB) has long been used in compromised neonatal foals to augment cardiac output by its primary action on $\beta 1$ - and only weak activation of $\beta 2$ - and 
$\alpha$-adrenoreceptors. Starting doses of $1-3 \mu \mathrm{g} / \mathrm{kg} / \mathrm{min}$ with subsequent titration to effect have been used in foals while closely monitoring for tachycardia, arrhythmia and other adverse reactions (Corley 2004). Increased $\mathrm{Cl}$ (100\%-210\% increase in $\mathrm{Cl}$ depending on the dose used), $\mathrm{MAP}, \mathrm{DO}_{2}$ and decreased oxygen extraction ratio have been reported following DOB administration in foals with anaesthesia-induced hypotension; similar results were obtained in healthy normotensive anaesthetized foals (Craig et al. 2007, Valverde et al. 2006). Based on the positive clinical responses observed by many clinicians, one can probably assume a similar cardiovascular effect in compromised neonatal foals.

Dopamine (DO) has been used in equine medicine as inotrop, vasopressor and to increase renal blood flow due to its dose dependent effect on dopaminergic, $\beta 1$-, $\beta 2$ - and $\alpha$ adrenergic receptors. However, evidence is accumulating that other drugs are more effective in either of the aforementioned functions. Its action on multiple receptors and the poor correlation between infusion rate and plasma levels (10- to 75fold differences in plasma concentrations for a given infusion rate have been reported in healthy human volunteers) make the actions of DO somewhat unpredictable as for a given infusion rate, depending on the patient, either dopaminergic, inotropic or vasopressor activities may dominate (MacGregor et al. 2000). A metaanalysis investigating the effects of inotropes on morbidity and mortality in preterm human infants with low systemic or organ blood flow concluded that DOB was more effective than DO in increasing and maintaining systemic blood flow (Osborn et al. 2007). To the autho$r$ 's knowledge, the effects of DO and DOB have not been directly compared in critically ill foals, but based on the well established beneficial effects of dobutamine and its almost exclusive action on $\beta 1$ receptors, it is probably the preferable drug for inotropic support in compromised foals.

\section{Vasopressors}

If peripheral perfusion and MAP remain low despite adequate intravascular volume and administration of inotropes, attempts should be made to achieve a sufficient vascular tone to establish a pressure gradient and promote blood flow through the peripheral organs. However, as not all organ systems are uniformly affected by either vasodilation or the administered vasopressor, their use always carries the risk of excessive vasoconstriction in some vascular beds, mainly the splanchnic circulation, thereby decreasing, rather than increasing, perfusion to those tissues. All patients receiving vasopressor therapy must be closely monitored for any signs of compromised, rather than improved, peripheral perfusion, as an increased MAP in response to the infusion can not be universally taken as evidence for improved end organ perfusion.

Norepinephrine (Noradrenaline; NE) is a strong $\alpha 1$-adrenergic agonist with some activity on $\beta 1$ and minimal $\beta 2$ receptor activity (Sakr et al. 2006). NE is advocated as first line vasopressor in severe sepsis and septic shock in human patients and limited data available on its use in hypotensive, critically ill foals unresponsive to fluid resuscitation and DOB or DO also encourages its use as a vasopressor (Corley 2000, Dellinger et al. 2008). Blood pressure increased in
6/7, and urine output increased in all foals treated with $N E$ in addition to either DOB or DO (Corley 2000). The cardiovascular effects of NE in healthy, normotensive, awake and in healthy foals with anesthesia-induced hypotension have been recently investigated. While NE $(0.1 \mu \mathrm{g} / \mathrm{kg} / \mathrm{min})$ with or without additional infusion of DOB increased MAP and SVR, but decreased $\mathrm{Cl}$ in normotensive foals (Hollis et al. 2006b), an increase in MAP, SVR and $\mathrm{Cl}$ was detected in hypotensive, anaesthetised foals treated with NE $(0.3$ and $1.0 \mu \mathrm{g} / \mathrm{kg} / \mathrm{min})$ alone (Valverde et al. 2006). Negative effects of NE on indices of either renal function or splanchnic circulation were not detected in the two studies (Hollis et al. 2006b, Valverde et al. 2006). Although results of these reports highlight the difficulties associated with extrapolation of data from one species to another and from experimental results to the clinical setting, the currently available evidence encourages the use of $\mathrm{NE}$, probably in combination with $\mathrm{DOB}$, as a vasopressor in hypotensive foals unresponsive fluid resuscitation and inotropes.

Vasopressin (VP) or anitdiuretic hormone (ADH) has received increasing attention in recent years due to its role as endogenous stress hormone and its importance in maintaining blood pressure during critical illness. VP is released in response to severe hypovolaemia, decreased cardiac filling and increased plasma osmolarity and its effects on the arterial vasculature are mediated via $\mathrm{V} 1$ receptors (Meyer et al. 2008, Treschan and Peters 2006). The vasoconstrictive properties of VP are much more pronounced in subjects suffering from enodtoxaemia or septic shock than under physiologic circumstances (Treschan and Peters 2006). Relative VP deficiency has been demonstrated in human patients with late septic shock and its use has been advocated in catecholamine-refractory hypotension, but significant side effects, namely potent splanchnic vasoconstriction and ischaemic skin necrosis, have raised concerns about its safety. Use of VP as a first line vasopressor is currently not recommended in treatment of human patients in septic shock, but it may be administered in addition to NOR in later stages of the treatment (Dellinger et al. 2008).

Endogenous VP levels in septic, non-septic and hypovolaemic foals and the effects of VP infusion on haemodynamic parameters in healthy foals have been studied. Higher VP concentrations were found in diseased, but non-septic foals and in septic foals compared to normal controls in two independent studies. In both studies VP concentrations were significantly higher in non-surviving septic foals compared to survivors (Hurcombe et al. 2007, Gold 2006), suggesting that either relative VP deficiency does not occur in septic neonatal foals to the same extend as it in human patients or that foals succumb to disease before a deficiency can manifest. Although authors of both studies speculated that increased VP concentrations may be associated with hypovolaemia and/or hypotension, a separate study did not detect increased plasma levels in 5 clinical cases of hypovolaemia in neonatal foals $<48 \mathrm{~h}$ of age. Blood pressure values of these foals were not reported and it is unknown whether hypovolaemia was associated with hypotension. Sepsis was not confirmed in any of these animals, but 3 suffered from PAS (Hollis et al. 2008). In contrast, significant increases in VP were found in 1 and 2 week old foals with pharmacologically induced hypotension (O'Connor et al. 2005). The studies are difficult to compare 
as one reports VP levels in very young foals with clinically identified hypovolaemia (Hollis et al. 2008) while the other measured VP levels in slightly older foals in response to pharmacologically induced hypotension (O'Connor et al. 2005). Clearly, further studies are needed to define the role of endogenous VP levels in critical illness in equine neonates.

VP infusion ( 0.3 and $1.0 \mathrm{mU} / \mathrm{kg} / \mathrm{min}$ ) administered to neonatal foals with anaesthesia-induced hypotension increased MAP and SVR and had no effect on $\mathrm{Cl}$ or SV. A significant increase in gastric to arterial $\mathrm{CO}_{2}$ gap during high dose VP infusions suggested gastric and possibly also splanchnic hypoperfusion, which was not observed with either DOB or NOR infusions (Valverde et al. 2006). Based on this information, NOR may currently be regarded as the safer option for vasopressor support in neonatal foals.

\section{Dopamine (DO)}

Although DO is still recommended as first line vasopressor in treatment of human patients with severe sepsis or septic shock (Dellinger et al. 2008), an increased mortality associated with administration of DO or epinephrine (adrenaline), but not NOR, has been reported in adult human patients with shock, leading to the suggestion that NE is the more reasonable choice (Sakr et al. 2006). A direct comparison between DO and NOR in critically ill foals has to the author's knowledge not been made, and, keeping limitations of both drugs in mind, either high doses of DO or NOR may be used for vasopressor support.

\section{Relative adrenal insufficiency}

Plasma cortisol levels increase in response to critical illness and are essential for maintaining vascular responses to catecholamines and angiotensin and modulation of the immune response. During relative adrenal insufficiency, the patient is not able to mount a cortical response adequate for the degree of illness imposed on the body. Although cortisol levels may be within the normal range, they are relatively too low for the demands of the patient. Symptoms include haemodynamic instability and refractory hypotension unresponsive to fluid and vasopressor therapy (Langer et al. 2006). Diagnosis, particularly in human neonates, is a matter of debate; most commonly, a low dose adrenocorticotropin hormone (ACTH) stimulation test is used. However, the optimal ACTH dose, timing of sampling and interpretation of results are far from being well established in human neonatal and pediatric critical care (Langer et al. 2006). Evaluation of several ACTH doses and sampling times in healthy 3-4 day old neonatal foals suggested that an intravenous dose of $10 \mu \mathrm{g}$ or $100 \mu \mathrm{g}$ per foal (approximately $50 \mathrm{~kg}$ ) and measurement of the cortisol response $30 \mathrm{~min}$ post injection may be appropriate (Hart et al. 2007). Relative adrenal insufficiency has been investigated in septic foals in two studies; both studies based the diagnosis on measurements of endogenous ACTH and cortisol levels and not on ACTH stimulation tests. The first study demonstrated higher mean $\mathrm{ACTH}$ and cortical levels and a higher ACTH/cortisol ratio in septic foals compared to healthy controls and non-surviving septic foals had higher ACTH/cortisol ratios than survivors (Gold et al. 2007). Results of the second study corroborated these findings, suggesting that relative adrenal insufficiency may exist in critically ill equine neonates and could influence survival (Hurcombe et al. 2007). Supplementation of critically ill neonates with clinical or laboratory signs of adrenal insufficiency may therefore be indicated. Unfortunately, little treatment guidelines for the best type of steroids, dose or duration of supplementation are available. Based on anecdotal reports, low doses of a short acting steroid, such as hydrocortisol, either as bolus or infusion, may be used.

\section{Respiratory support}

Tissue hypoxia is not only dependent on adequate perfusion, but also on adequate $\mathrm{CaO}_{2}$ and $\mathrm{O}_{2}$ transport in the blood. Pulmonary dysfunction is a common problem in critically ill equine neonates and pulmonary radiographic abnormalities have been identified in up to $74 \%$ of hospitalized neonates (Bedenice et al. 2003). Underlying pathologies may include pulmonary immaturity and associated surfactant dysfunction, a disease for which the term neonatal equine respiratory distress syndrome (NERDS) has been recently suggested(PA Wilkins et al. 2007), bacterial pneumonia, often associated with sepsis or aspiration, viral pneumonia, meconium aspiration and acute lung injury/acute respiratory distress, recently termed equine neonatal acute lung injury/acute respiratory distress (EqNALI/EqNARDS) (Peek et al. 2004, Wilkins 2004, Wilkins et al. 2007). Other causes associated with hypoxaemia/hypoxia include persistent pulmonary hypertension (PPH), primary cardiac abnormalities, particularly if right-toleft shunting is present, anaemia, for example due to neonatal isoerythrolysis, and centrally mediated hypoventilation, often in connection with PAS (Wilkins 2004).

Regardless of the underlying pathology, tissue oxygenation can be improved by two basic interventions: increasing $\mathrm{CaO}_{2}$ and/or increasing perfusion and therefore $\mathrm{O}_{2}$ transport to the tissues.

$\mathrm{CaO}_{2}$ of the blood can be increased by increasing the percentage of $\mathrm{O}_{2}$ saturation $\left(\mathrm{SaO}_{2}\right)$ and partial arterial pressure of $\mathrm{O}_{2}\left(\mathrm{PaO}_{2}\right)$ by intranasal oxygen insufflation, improving dead space ventilation, counteracting centrally mediated hypoventilation and, if necessary, mechanical ventilation. Alternatively, the $\mathrm{O}_{2}$ transport capacity can be optimsed by increasing the haemoglobin concentration of the blood (whole blood transfusion or haemoglobin based $\mathrm{O}_{2}$ carrier).

\section{Intranasal $\mathrm{O}_{2}$ insufflation}

The ability of intranasal oxygen insufflation to increase $\mathrm{SaO}_{2}$ and $\mathrm{PaO}_{2}$ depends on the underlying pathophysiology: small intrapulmonary shunt fractions respond very favorably to increases in $\mathrm{FiO}_{2}$ while dead space ventilation or intrapulmonary shunt fractions in excess of $50 \%$ are almost non-responsive to exogenous $\mathrm{O}_{2}$ administration, regardless of the flow rate chosen. The resistance $(\mathrm{R})$ to $\mathrm{O}_{2}$ flow is inversely proportional to the diameter $\left(R \sim 1 / r^{4}\right)$ and directly proportional to the length of the tubing system used $(R \sim l)$, indicating that the shortest tubing with the largest diameter provides the least resistance to $\mathrm{O}_{2}$ flow and results in the highest flow rates deli- 
vered to the patient. Bilateral intranasal cannulas connected to two separate flow regulators or two $\mathrm{O}_{2}$ sources allow delivery of flow rates up to $30 \mathrm{~L} / \mathrm{min}, 15 \mathrm{~L} / \mathrm{min}$ in each nostril. However, as oxygen toxicity is a thread with administration of high $\mathrm{FiO}_{2}$, also to the author's knowledge not reported in foals, the lowest possible flow rate should be chosen (Sinha and Tin 2003).

\section{Improving respiratory efficiency}

Hypoxaemia and hypercapnia without underlying pulmonary pathology occur in equine neonates with PAS. These foals demonstrate inappropriately low or irregular respiratory rates or periods of apnoea resulting in severe respiratory acidosis. Lack of central detection of the increased $\mathrm{PaCO}_{2}$ by the chemosensitive areas in the respiratory center is thought to be the underlying cause of the condition (Giguere et al. 2008). Treatment options for centrally mediated hypoventilation include pharmacological stimulation of the respiratory centre using caffeine or doxapram or mechanical ventilation. Orally or rectally administered caffeine $(10 \mathrm{mg} / \mathrm{kg}$ loading dose $\mathrm{PO} /$ dissolved orally or per rectum; then $2.5-5.0 \mathrm{mg} / \mathrm{kg}$ as needed) has been used clinically with anecdotally reported success (Palmer 2005, Wilkins 2004). Doxapram may be administered as a continuous rate infusion (loading dose $0.5 \mathrm{mg} / \mathrm{kg}$ followed by $0.02-0.08 \mathrm{mg} / \mathrm{kg} / \mathrm{min}$ ) (Giguere et al. 2007, Giguere et al. 2008). The effects of caffeine and doxapram in improving respiratory function in neonatal foals have been investigated experimentally in anaesthesia-induced hypoventilation and retrospectively in clinical cases of foals with PAS (Giguere et al. 2007, Giguere et al. 2008). In the experimental study, no effects on respiratory and arterial blood gas values were observed following caffeine administration, despite achievement of serum levels within the therapeutic range reported for other species, while infusion of doxapram resulted in increased respiratory rate, minute ventilation, $\mathrm{pH}$ and $\mathrm{PaO}_{2}$ and significantly decreased $\mathrm{PaCO}_{2}$ (Giguere et al. 2007). Similar effects of doxapram were observed in clinical cases, although $\mathrm{pH}$ was not significantly altered by the treatment; caffeine administration did not result in any significant changes in respiratory or acid base parameters measured (Giguere et al. 2008). Based on the information currently available, doxapram is probably the treatment of choice for centrally mediated hypoventilation in neonatal foals, bearing in mind that adverse effects and safety of the drug have not been established in a large number of foals.

If the desired results can not be achieved with caffeine or doxapram, mechanical ventilation may be indicated. The principles of mechanical ventilation in foals have been reviewed in detail elsewhere (Palmer 2005).

Decreased respiratory efficiency due to pain associated with breathing, for example in foals with fractured ribs or pleuropneumonia, can be improved by providing analgesia, either by careful use of non-steroidal anti-inflammatory drugs (NSAIDs) or opioids such as butorphanol.

Further options include increasing $\mathrm{CO}$ which may augment pulmonary perfusion sufficiently to limit dead space ventilation and improve ventilation/perfusion matching.
Increasing $\mathrm{O}_{2}$ carrying capacity

Oxyhaemoglobin accounts for approximately $98 \%$ of the total $\mathrm{CaO}_{2}$ in the blood while $\mathrm{PaO}_{2}$ only adds $1-2 \%$. Even mild anaemia is therefore much more likely to result in tissue hypoxia than moderate to severely reduced $\mathrm{PaO}_{2}$ levels. Indications for blood transfusions depend largely on the individual patient. Patients with anaemia and concurrent pulmonary disease may require a transfusion much earlier to maintain an adequate $\mathrm{CaO}_{2}$ than patients without pulmonary compromise. An increased plasma lactate concentration and decreased mixed venous oxygen saturation $\left(\mathrm{SvO}_{2}\right)$ or mixed venous $\mathrm{PvO}_{2}$ despite sufficient volume resuscitation and signs of adequate peripheral perfusion may indicate the need for a transfusion in patients with a low or low-normal haematocrit. However, the expected benefits must be weight carefully against the potential risks associated with blood transfusions. The $\mathrm{O}_{2}$ carrying capacity can be increased by administration of whole blood, red blood cell concentrates or an haemoglobin-based oxygen carrier such as oxyglobin ${ }^{\circledR}$. The clinical use of haemoglobin-based oxygen carriers has been described in a foal (Perkins and Divers 2001) and adult horses (Maxson et al. 1993, Vin et al. 2002) and cardiovascular effects and pharmacokinetics have been established in adult horses (Belgrave et al. 2002, Soma et al. 2005). Haemoglobin-based oxygen carrier may provide an alternative haemoglobin source if whole blood is not rapidly available.

\section{Support of renal function}

Signs of compromised renal function, either in form of increased serum creatinine concentrations or decreased urine production may be seen as part of PAS or sepsis and may be prerenal, renal or postrenal in origin. A sudden decrease in previously adequate urine production may indicate worsening of renal perfusion subsequent to worsening of overall cardiovascular function. The best support for renal protection and function is without question prevention or immediate treatment of hypovolaemia and hypotension and improvement of peripheral perfusion and $\mathrm{O}_{2}$ delivery as described. Neither diuretics nor any pharmacologic agent aiming to improve specifically renal perfusion or limit renal inflammation have been shown to improve outcome in human studies of renal failure (De Vriese and Bourgeois 2003). Nevertheless, attempts are occasionally been made to selectively improve renal perfusion. Post renal failure must be ruled out in any critically ill neonate with decraeser urine output, as it may develop during hospitalization, as discussed below (Dunkel et al. 2005, Kablack et al. 2000).

\section{Dopamine}

Although its use in low doses has long been advocated to improve renal perfusion by activation of dopaminergic receptors, the efficacy of DO in establishing renal blood flow and urine output has been increasingly challenged and the use of DO in renal failure or for purposes of renal protection is currently no longer recommended (Bellomo et al. 2008, Dellinger et al. 2008, Sakr et al. 2006). 
Fenoldopam

Low dose rates of fenoldopam (0.03-0.05 $\mu \mathrm{g} / \mathrm{kg} / \mathrm{min})$, a selective dopamine 1 receptor agonist, have been reported to increase renal blood flow and urine output in normotensive humans and two doses of fenoldopam have been investigated in healthy, conscious normotensive 3-5 days old foals. The low dose $(0.04 \mu \mathrm{g} / \mathrm{kg} / \mathrm{min})$ increased urine output without showing effects on haemodynamics or creatinine clearance, while the high dose did not affect renal function, but decreased blood pressure and increases in heart rate were noted (Hollis et al. 2006a). The authors concluded that fenoldopam at low doses has the potential for prophylaxis and treatment of renal failure in critically ill foals, however, further studies are required until its use can be recommended.

Postrenal failure in form of uroperitoneum is not uncommon in neonatal foals and may develop during hospitalization in critically ill neonates. An association between the development of uroperitoneum and hypoxic insults, infection and sepsis has been suggested (Dunkel et al. 2005). The classic electrolyte abnormalities associated with the condition, namely hyponatraemia, hypochloraemia and hyperkalaemia may not be observed in foals receiving intravenous fluid therapy and the disease may only manifest as increased serum creatinine concentration and sudden decrease in urine production (Dunkel et al. 2005, Kablack et al. 2000). Diagnosis is best established by ultrasonographic examination of the abdomen.

\section{Nutritional support}

Provision of adequate nutrition is an essential part of supportive care for the compromised neonate. Although enteral nutrition is the preferable option whenever possible, few compromised neonates tolerate sufficient quantities to meet their daily caloric requirements. Gastrointestinal compromise may manifest as mild to moderate abdominal distension, colic, diarrhoea or nasogastric reflux. Colic signs can be subtle, particularly if the patient is weak or mentally obtunded and may only become apparent in restlessness, stretching and shifting into a more dorsal position. If any doubt exists whether enteral nutrition will be tolerated, the patient is best provided with some form of parenteral nutrition until a sufficient caloric intake is guarantied. Assuming a milk intake of $20-30 \%$ of its body weight and a caloric content of $500-600 \mathrm{kcal} / \mathrm{L}$ of mare's milk, a healthy, active, growing foal consumes approximately 100$180 \mathrm{kcal} / \mathrm{kg} / \mathrm{d}$ (Paradis 2003). The caloric requirements of critically ill neonates are probably lower, measurements using indirect calorimetry indicated resting energy requirements in the range of $40-50 \mathrm{kcal} / \mathrm{kg} / \mathrm{d}$ (Paradis 2001).

\section{Enteral nutrition}

If the foal is ambulatory and has a strong suckle reflex, it can be allowed to nurse from the mare. If the foal is unable to stand or a sufficient suckle reflex is not present, enteral nutrition is best provided via an indwelling nasogastric feeding tub. Due to the substantial risk of aspiration, recumbent neonates may better be fed via an indwelling nasogastric tube, even if a suckle reflex is present, until they have gained sufficient strength to stand and nurse from the mare. A soft, small dia- meter feeding tube allows the foal to suck with the tube in place and can be used to supplement the foal enterally if an adequate intake is not yet achieved by nursing. Mare's milk is the best source of nutrition; some clinicians feel that colostrums is even better tolerated and may be the most suitable source of nutrition for the first enteral feedings of a foal recovering from severe illness. The starting volume depends very much on the degree of compromise: in less severe cases, initial feedings of $5-10 \%$ of the body weight/day with relatively quick increases in volume within 2-3 days to the full feeding of $25 \%$ of the body weight/day, administered every $2-4 \mathrm{~h}$, may be achievable. Severely compromised neonates on the other hand may benefit from feeding of very small quantities, so called trophic feeding, (1\% of body weight/day divided in hourly feedings) with minimal or no increases in volume until the foal has sufficiently recovered, to enhance maturation of the gastrointestinal system and maintain the gut barrier. Any foal not receiving full enteral feeding should be supplemented with at least intravenous glucose or, ideally, parenteral nutrition.

\section{Parenteral nutrition}

Parenteral nutritional support can be provided in form of a glucose infusion, glucose-amino acid solutions or a glucoseamino acid-lipid combination. The glucose oxidation rate in human pediatric patients ranges from $4-8 \mathrm{mg} / \mathrm{kg} / \mathrm{min}$ and similar rates are recommended for equine neonates (Palmer 2004, Spurlock and Ward 1991, Wilkins 2004), provided as $5 \%$ or $10 \%$ dextrose in water or with dextrose added to the maintenance fluids. Alternatively, 50\% dextrose solution can be added via an infusion pump to the maintenance fluids. Dextrose concentrations of up to $25 \%$ have been administered to equine patients via the jugular vein without complications (Spurlock 1990), but use of lower concentration is probably advisable to avoid unnecessary irritation of the veins. Using the approach outlined above, dextrose alone can provide $20-40 \mathrm{kcal} / \mathrm{kg} / \mathrm{d}$ (1 g glucose $=3.4 \mathrm{kcal})$.

Several reviews on the principles of parenteral nutrition in foals have been published (Buechner-Maxwell 2005, Dunkel and Wilkins 2004, Koterba and Drummond 1985, Paradis 2003); in short, glucose and lipids in varying ratios (40-70\% of energy requirements met by glucose and $30-60 \%$ by lipids) are used to provide the caloric requirements of the patient while amino acids are supplied for protein synthesis and to minimise endogenous protein break down (Lopes and White 2002, Spurlock and Ward 1991). While healthy nursing foals consume approximately $5-6 \mathrm{~g} / \mathrm{kg} / \mathrm{d}$ of protein, amino acids at a rate of $2-3 \mathrm{~g} / \mathrm{kg} / \mathrm{d}$ are often used in parenteral formulations for compromised equine neonates (Hansen 1990, Spurlock and Ward 1991). A parenteral solution providing $10 \mathrm{~g} / \mathrm{kg} / \mathrm{g}$ glucose, $2 \mathrm{~g} / \mathrm{kg} / \mathrm{d}$ amino acids and $1 \mathrm{~g} / \mathrm{kg} / \mathrm{d}$ lipids can be formulated by mixing $1000 \mathrm{ml}$ of $50 \%$ dextrose in water with $1000 \mathrm{ml}$ of $10 \%$ amino acid solution and $500 \mathrm{ml}$ of $10 \%$ lipid emulsion under sterile conditions in a flow hood. The final infusion rate for a $50 \mathrm{~kg}$ foal is $104 \mathrm{ml} / \mathrm{h}$ and provides $53 \mathrm{kcal} / \mathrm{kg} / \mathrm{d}$. Potassium chloride and multivitamins may be added to the solution as needed. Infusions are commonly started at $25-50 \%$ of the target rate and gradually increased over 24-48h to the full rate (Krause and McKenzie 2007). Blood glucose concentrations should be monitored every 46h initially which can be reduced to twice daily monitoring 
once the patient is stable. As the condition of the patient improves and at least partial enteral nutrition has been successfully introduced, parenteral nutrition is gradually decreased and discontinued over 24-48h, depending on the enteral intake at the time.

The most common complication encountered in foals receiving parenteral nutrition is hyperglycaemia. One study reported blood glucose concentrations $>10 \mathrm{mmol} / \mathrm{L}$ in $62 \%$ of foals receiving parenteral nutrition; other complications included hyperlipidaemia (plasma triglycerides $>0.6 \mathrm{mmol} / \mathrm{L}$ ) in $11 \%$ and phlebitis in 6\% of the foals (Krause and McKenzie 2007).

Approaches to hyperglycaemia vary significantly among clinicians. Benign neglect may be reasonable unless hyperglycaemia is severe or osmotic diuresis occurs. Glucosuria is easily identified by the use of urinary dip sticks and signifies the need for intervention. Continuous rate infusion of regular insulin is indicated in these cases. Reduction of the glucose or parenteral nutrition infusion rate is counterproductive as the energy requirements of the foals will not be met. Recommended insulin infusion rates range from $0.001-0.21 \mathrm{U} / \mathrm{kg} / \mathrm{h}$, beginning at a low rate followed by titration to effect under frequent monitoring of the blood glucose concentration (Krause and McKenzie 2007, Paradis 2003, Wilkins 2004).

Tight glucose control between 80-110mg/dl (4.4$6.1 \mathrm{mmol} / \mathrm{L}$ ) using intensive insulin therapy has been associated with decreased morbidity and mortality in critically ill human patients (van den Berghe et al. 2001, Verbruggen et al. 2007) and benefits and risks of this treatment strategy are currently much debated in human critical care. Hyperglycaemia is associated with non-survival in adult horses with acute abdominal disease (Hollis et al. 2007) and occurrence of hyperglycaemia and requirement for insulin therapy were associated with non-survival in foals receiving parenteral nutrition (Krause and McKenzie 2007). In human medicine, the most frequently observed complication of insulin therapy is, sometimes severe, hypoglycaemia, particularly in neonates and children and it is currently unknown whether benefits will outweigh the risks associated with tight glucose control in this patient population (Verbruggen et al. 2007). From a practical view, tight glucose control is associated with a significant increase in workload for the nursing staff and deviations from the protocol are common even in the point of face of vigorous monitoring (Malesker et al. 2007). Successful tight glucose control without exposing the patient to the substantial risks of iatrogenic hypoglycaemia will most likely only be feasible in equine intensive care unites with a sufficient number of exquisitely well trained nursing personnel. If adequate patient supervision can not be provided, a less stringent approach to glucose control may be advisable.

\section{References}

Bedenice D., Heuwieser W., Solano M., Rand W. and Paradis M. R. (2003) Risk factors and prognostic variables for survival of foals with radiographic evidence of pulmonary disease. J. Vet. Intern. Med. 17, 868-875

Belgrave R. L., Hines M. T., Keegan R. D., Wardrop K. J., Bayly W. M. and Sellon D. C. (2002) Effects of a polymerized ultrapurified bovine hemoglobin blood substitute administered to ponies with normovolemic anemia. J. Vet. Intern. Med. 16, 396-403
Bellomo R., Wan L. and May C. (2008) Vasoactive drugs and acute kidney injury. Crit. Care. Med. 36, S179-186

Buchanan B. R., Sommardahl C. S., Rohrbach B. W. and Andrews F. M. (2005) Effect of a 24-hour infusion of an isotonic electrolyte replacement fluid on the renal clearance of electrolytes in healthy neonatal foals. J. Am. Vet. Med. Assoc. 227, $1123-1129$

Buechner-Maxwell V. A. (2005) Nutritional support for neonatal foals. Vet. Clin. North Am. Equine Pract. 21, 487-510, viii

Corley K. T. (2000) Initial Experience with Norepinephrine Infusion in Hypotensive Critically III Foals. J. Vet. Emerg. Crit. Care 10, $267-$ 276

Corley K. T. (2004) Inotropes and vasopressors in adults and foals. Vet. Clin. North Am. Equine Pract. 20, 77-106

Craig C. A., Haskins S.C. and Hildebrand S. V. (2007) The cardiopulmonary effects of dobutamine and norepinephrine in isoflurane-anesthetized foals. Vet. Anaesth. Analg. 34, 377-387

De Vriese A. S. and Bourgeois M. (2003) Pharmacologic treatment of acute renal failure in sepsis. Curr. Opin. Crit. Care 9, 474-480

Dellinger R. P., Levy M. M., Carlet J. M., Bion J., Parker M. M., Jaeschke R., Reinhart K., Angus D. C., Brun-Buisson C., Beale R., Calandra T., Dhainaut J. F., Gerlach H., Harvey M., Marini J. J., Marshall J., Ranieri M., Ramsay G., Sevransky J., Thompson B. T., Townsend S., Vender J. S., Zimmerman J. L. and Vincent J. L. (2008) Surviving Sepsis Campaign: international guidelines for management of severe sepsis and septic shock: 2008. Crit. Care Med. 36, 296-327

Dunkel B., Palmer J. E., Olson K. N., Boston R. C. and Wilkins P. A. (2005) Uroperitoneum in 32 foals: influence of intravenous fluid therapy, infection, and sepsis. J. Vet. Intern. Med. 19, 889-893

Dunkel B. M. and Wilkins P. A. (2004) Nutrition and the critically ill horse. Vet. Clin. North Am. Equine Pract. 20, 107-126

Giguere S., Sanchez L. C., Shih A., Szabo N. J., Womble A. Y. and Robertson S. A. (2007) Comparison of the effects of caffeine and doxapram on respiratory and cardiovascular function in foals with induced respiratory acidosis. Am. J. Vet. Res. 68, 1407-1416

Giguere S., Slade J. K. and Sanchez L. C. (2008) Retrospective comparison of caffeine and doxapram for the treatment of hypercapnia in foals with hypoxic-ischemic encephalopathy. J. Vet. Intern. Med. 22, 401-405

Gold J. R., Divers T .J., Barton M. H., Lamb S. V., Place N. J., Mohammed H. O. and Bain F. T. (2007) Plasma adrenocorticotropin, cortisol, and adrenocorticotropin/cortisol ratios in septic and normal-term foals. J. Vet. Intern. Med. 21, 791-796

Hansen T. O. (1990) Nutritional support: parenteral feeding, Lea \& Febiger, Philadelphia

Hart K. A., Ferguson D. C., Heusner G. L. and Barton M. H. (2007) Synthetic adrenocorticotropic hormone stimulation tests in healthy neonatal foals. J. Vet. Intern. Med. 21, 314-321

Hollis A. R., Boston R. C. and Corley K. T. (2007) Blood glucose in horses with acute abdominal disease. J. Vet. Intern. Med. 21, 1099-1103

Hollis A. R., Boston R. C. and Corley K. T. (2008) Plasma aldosterone, vasopressin and atrial natriuretic peptide in hypovolaemia: a preliminary comparative study of neonatal and mature horses. Equine Vet. J. 40, 64-69

Hollis A. R., Ousey J. C., Palmer L., Stoneham S. J. and Corley K. T. (2006a) Effects of fenoldopam mesylate on systemic hemodynamics and indices of renal function in normotensive neonatal foals. J. Vet. Intern. Med. 20, 595-600

Hollis A. R., Ousey J. C., Palmer L., Stoneham S. J. and Corley K. T. (2006b) Effects of norepinephrine and a combined norepinephrine and dobutamine infusion on systemic hemodynamics and indices of renal function in normotensive neonatal thoroughbred foals. J. Vet. Intern. Med. 20, 1437-1442

Hurcombe S. D. A., Toribio R. E., Slovis N., Kohn C. W. and Mudge M. C. (2007) Vasopressin, ACTH and Cortisol concentrations in sepric foals: Correlates with survival and nonsurvival. J. Vet. Intern. Med. 21, 582

Gold J. R., Divers T. J., Barton M.H., Lamb S. V., Place N. J., Mohammed H. O. and Bain F. T. (2006) ACTH, Cortisol and Vasopressin levels of sepric (survivors and nonsurvivors) in comparision to normal foals. J. Vet. Intern. Med. 20, 720 
Kablack K. A., Embertson R. M., Bernard W. V., Bramlage L. R., Hance S., Reimer J. M. and Barton M. H. (2000) Uroperitoneum in the hospitalised equine neonate: retrospective study of 31 cases, 1988-1997. Equine Vet. J. 32, 505-508

Koterba A. M. and Drummond W. H. (1985) Nutritional support of the foal during intensive care. Vet. Clin. North Am. Equine Pract. $1,35-40$

Krause J. B. and McKenzie H. C. 3rd (2007) Parenteral nutrition in foals: a retrospective study of 45 cases (2000-2004). Equine Vet. J. 39, 74-78.

Langer M., Modi B. P. and Agus M. (2006) Adrenal insufficiency in the critically ill neonate and child. Curr. Opin. Pediatr. 18, 448453

Lopes M. A. and White N. A. 2nd (2002) Parenteral nutrition for horses with gastrointestinal disease: a retrospective study of 79 cases. Equine Vet. J. 34, 250-257

MacGregor D. A., Smith T. E., Prielipp R. C., Butterworth J. F., James R. L. and Scuderi P. E. (2000) Pharmacokinetics of dopamine in healthy male subjects. Anesthesiology 92, 338-346

Magdesian K. G. (2004) Monitoring the critically ill equine patient. Vet. Clin. North Am. Equine Pract. 20, 11-39

Magdesian K. G. (2005) Neonatal foal diarrhea. Vet. Clin. North Am. Equine Pract. 21, 295-312, vi

Magdesian K. G. and Madigan J. E. (2003) Volume replacement in the neonatal ICU: crystalloids and colloids. Clin. Tech. Equine Pract. 2, 20-30

Malesker M. A., Foral P. A., McPhillips A. C., Christensen K. J., Chang J. A. and Hilleman D. E. (2007) An efficiency evaluation of protocols for tight glycemic control in intensive care units. Am. J. Crit. Care 16, 589-598

Maxson A. D., Giger U., Sweeney C. R., Tomasic M., Saik J. E., Donawick W. J. and Cothran E. G. (1993) Use of a bovine hemoglobin preparation in the treatment of cyclic ovarian hemorrhage in a miniature horse. J. Am. Vet. Med. Assoc. 203, 1308-1311

Meyer S., Gortner L., McGuire W., Baghai A. and Gottschling S. (2008) Vasopressin in catecholamine-refractory shock in children. Anaesthesia 63, 228-234

O'Connor S. J., Gardner D. S., Ousey J. C., Holdstock N., Rossdale P., Edwards C. M., Fowden A. L. and Giussani D. A. (2005) Development of baroreflex and endocrine responses to hypotensive stress in newborn foals and lambs. Pflugers Arch. 450, 298-306

Osborn D. A., Paradis M. and Evans N. (2007) The effect of inotropes on morbidity and mortality in preterm infants with low systemic or organ blood flow. Cochrane database of systematic reviews (Online), CD005090

Palmer J. E. (2004) Fluid therapy in the neonate: not your mother's fluid space. Vet. Clin. North Am. Equine Pract. 20, 63-75

Palmer J. E. (2005) Ventilatory support of the critically ill foal. Vet. Clin. North Am. Equine Pract. 21, 457-486, vii-viii

Paradis M. (2001) Nutrition and indirect calorimetry in neonatal foals. Proceedings of the 19th American College of Veterinary Internal Medicine Forum, Lakewood CO, 245-247

Paradis M. (2003) Nutritional support: enteral and parenteral. Clini. Tech. Equine Pract. 2, 87-95

Peek S. F., Landolt G., Karasin A. I., Slack J. A., Steinberg H., Semrad S. D. and Olsen C. W. (2004) Acute respiratory distress syndrome and fatal interstitial pneumonia associated with equine influenza in a neonatal foal. J. Vet. Intern. Med. 18, 132-134

Perkins G. A. and Divers T. J. (2001) Polymerized hemoglobin therapy in a foal with neonatal isoerythrolysis. J. Vet. Emerg. Crit. Care 11, 141-146
Sakr Y., Reinhart K., Vincent J. L., Sprung C. L., Moreno R., Ranieri V. M., De Backer D. and Payen D. (2006) Does dopamine administration in shock influence outcome? Results of the Sepsis Occurrence in Acutely III Patients (SOAP) Study. Crit. Care Med. 34, 589-597

Sinha S. K. and Tin W. (2003) The controversies surrounding oxygen therapy in neonatal intensive care units. Curr. Opin. Pediatr. 15, $161-165$

Slack J. A., McGuirk S. M., Erb H. N., Lien L., Coombs D., Semrad S. D., Riseberg A., Marques F., Darien B., Fallon L., Burns P., Murakami M. A., Apple F. S. and Peek S. F. (2005) Biochemical markers of cardiac injury in normal, surviving septic, or nonsurviving septic neonatal foals. J. Vet. Intern. Med. 19, 577-580

Soma L. R., Uboh C. E., Guan F., Luo Y., Moate P. J., Boston R. C. and Driessen B. (2005) The pharmacokinetics of hemoglobinbased oxygen carrier hemoglobin glutamer-200 bovine in the horse. Anesth. Analg. 100, 1570-1575

Spurlock S. L. (1990) Providing parenteral nutritional support for equine patients. Vet. Med. 85, 883-890

Spurlock S. L. and Ward M. V. (1991) Parenteral nutrition in equine patients: principles and theory. Comp. Cont. Educ. Pract. Vet 13, $461-468$

Thomas W. P., Madigan J. E., Backus K. Q. and Powell W. E. (1987) Systemic and pulmonary haemodynamics in normal neonatal foals. J. Reprod. Fertil. Suppl. 35, 623-628

Treschan T. A. and Peters J. (2006) The vasopressin system: physiology and clinical strategies. Anesthesiology 105, 599-612; quiz 639-540

Valverde A., Giguere S., Sanchez L. C., Shih A. and Ryan C. (2006) Effects of dobutamine, norepinephrine, and vasopressin on cardiovascular function in anesthetized neonatal foals with induced hypotension. Am. J. Vet. Res. 67, 1730-1737

van den Berghe G., Wouters P., Weekers F., Verwaest C., Bruyninkkx, F., Schetz M., Vlasselaers D., Ferdinande P., Lauwers P. and Bovillon R. (2001) Intensive insulin therapy in the critically ill patients. N. Engl. J. Med. 345, 1359-1367

Verbruggen S. C., Joosten K. F., Castillo L. and van Goudoever J. B. (2007) Insulin therapy in the pediatric intensive care unit. Clin. Nutr. 26, 677-690

Vin R., Bedenice D., Rentko V. T. and Paradis M. R. (2002) The use of ultrapurified bovine hemoglobin solution in the treatment of two cases of presumed red maple toxicosis in a miniature horse and a pony. J. Vet. Emerg. Crit. Care 12, 169-175

Wilkins P. A. (2004) Disorders of foals, 2 edn., Saunders, St. Louis, Missouri 63146. pp 1381-1431

Wilkins P. A., Otto C. M., Dunkel B., Bedenice D., Paradis M. R., Staffieri F., Baumgardner J. E., Syring R. S., Slack J., Grasso S. and Pranzo G. (2007) Acute lung injury and acute respiratory distress syndromes in veterinary medicine: consensus definitions: The Dorothy Russell Havemeyer Working Group on ALI and ARDS in Vet. Medicine. J. Vet. Emerg. Crit. Care 17, 333-339

Bettina Dunkel, DVM, DACVIM, DACVECC

The Royal Veterinary College

Department of Veterinary Basic Sciences

Hawkshead Lane,

North Mymms

Herts AL9 7TA

United Kingdom

bdunkel@rvc.ac.uk 